\title{
Açık Kalp Cerrahisi Sonrası Hastaların Fiziksel ve Psikososyal İyileşme Durumları
}

\author{
Sema KOÇAŞLI ${ }^{1}$ (D) Nevin KANAN ${ }^{2}$ (iD \\ ${ }^{1}$ Ankara Yıldırım Beyazıt Üniversitesi, Sağlık Bilimleri Fakültesi, Hemşirelik Bölümü, Ankara, Türkiye \\ skocasli@yahoo.com (Sorumlu Yazar/Corresponding Author) \\ ${ }^{2}$ İstanbul Üniversitesi Cerrahpaşa Florence Nigthingale Hemşirelik Fakültesi, Hemşirelik Bölümü, İstanbul, \\ Türkiye, nevkanan@yahoo.com
}

\begin{tabular}{|c|c|}
\hline Makale Bilgileri & $\mathbf{Z}$ \\
\hline \multirow[t]{2}{*}{$\begin{array}{l}\text { Anahtar Kelimeler: } \\
\text { Açık kalp ameliyat1, } \\
\text { Geçerlik-güvenirlik, } \\
\text { Yaşam kalitesi, } \\
\text { Hemşirelik bakımı. }\end{array}$} & 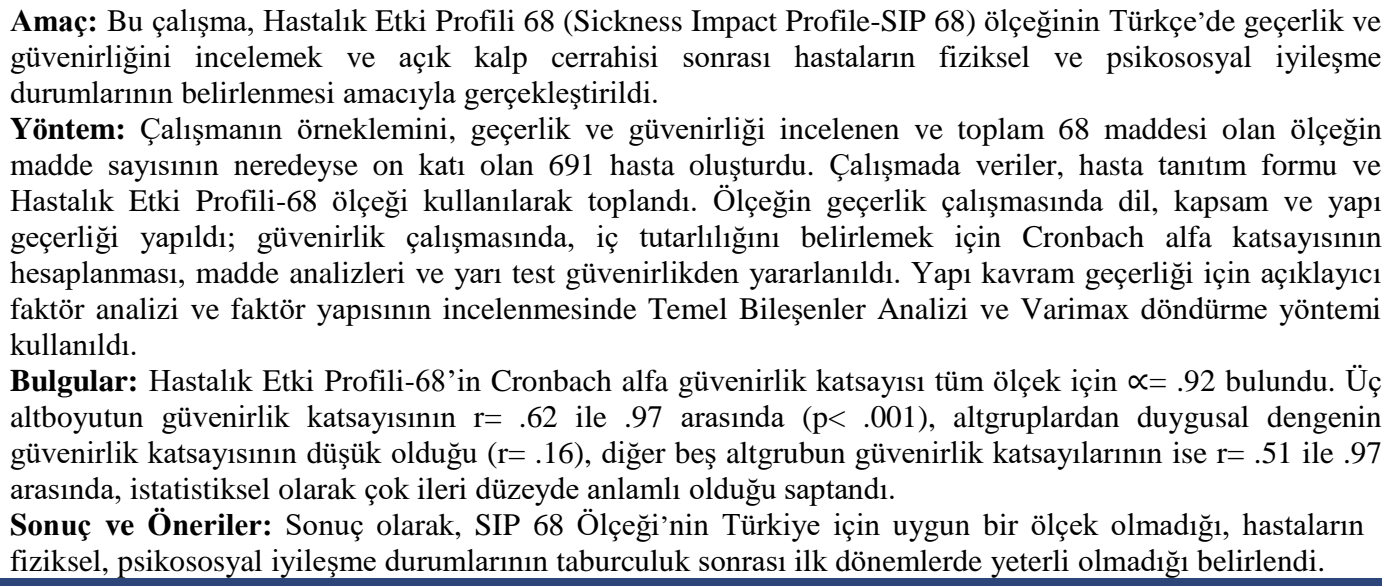 \\
\hline & $\begin{array}{c}\text { Physical and Psychosocial Recovery Patterns of Patients After Open } \\
\text { Heart Surgery }\end{array}$ \\
\hline Article Info & ABSTRACT \\
\hline $\begin{array}{l}\text { Article History } \\
\text { Received: } 09.10 .2020 \\
\text { Accepted: } 15.12 .2020 \\
\text { Published: } 25.12 .2020 \\
\text { Keywords: } \\
\text { Open heart surgery, } \\
\text { Validity-reliability, } \\
\text { Quality of life, } \\
\text { Nursing care. }\end{array}$ & $\begin{array}{l}\text { Pupose: This study was carried out as a methodological and descriptive-correlational type research } \\
\text { to examine the validity and reliability of the Disease Impact Profile } 68 \text { (Sckness Impact Profile-SIP } \\
68 \text { ) scale in Turkish and to determine the physical and psychosocial recovery status of patients } \\
\text { after open heart surgery. } \\
\text { Method: The sample consisted of } 691 \text { patients whose validity and reliability were examined in the } \\
\text { study and almost ten times the number of items of the scale with } 68 \text { items. Data in the study were } \\
\text { collected using the patient identification form and the Disease Impact Profile- } 68 \text { scale. In the } \\
\text { validity study of the scale, language, content and construct validity were done; In the reliability } \\
\text { study, calculation of Cronbach alpha coefficient, item analysis and quasi-test reliability were used } \\
\text { to determine internal consistency. Principal Component Analysis and Varimax rotation method } \\
\text { were used in explanatory factor analysis for construct concept validity and in examining factor } \\
\text { structure. } \\
\text { Results: The Cronbach alpha reliability coefficient of the Disease Effect Profile- } 68 \text { was found to } \\
\text { be }=.92 \text { for the whole scale. The reliability coefficient of the three sub-dimensions is between } r= \\
.62 \text { and } .97 \text { (p <.001), the emotional balance among the subgroups has a low reliability coefficient } \\
\text { (r }=.16 \text { ). Between } .97 \text {, it was found to be statistically very highly significant. } \\
\text { Conclusions and Recommendation: As a result, Scale SIP } 68 \text { is not an appropriate measure for } \\
\text { Turkey, patients' physical, it was determined that not enough psychosocial healing in the first } \\
\text { period after discharge status. }\end{array}$ \\
\hline
\end{tabular}

Atıf/Citation: Koçaşlı, S. \& Kanan, N. (2020). Açık kalp cerrahisi sonrası hastaların fiziksel ve psikososyal iyileşme durumları, Genel Să̆lık Bilimleri Dergisi, 2(3), 146-158. 


\section{GíRIŞ}

Koroner arter hastalığı, gelişmiş ülkelerde olduğu gibi ülkemizde de hastalık ve ölüm nedenleri arasında ilk sıralarda yer alır. Etkili, güvenilir ve yaygın tedavi seçenekleri arasında açık kalp cerrahisi gelmektedir (Onat ve Can 2017; World Health Organization [WHO], 2017); Republic of Turkey Ministry of Health 2015). Bu amaçla sıklıkla koroner arter bypass greft (KABG) ve kalp kapak ameliyatları yapılmaktadır (Doğu vd., 2015). Açık kalp cerrahisi, hastanın yaşam kalitesi ve süresinin artmasında ve hastalığın olası komplikasyonlarını önlemede etkili bir yöntem olmasının yanı sıra birçok sistemin etkilenmesine neden olmaktadır. Ayrıca, ameliyat sonrası süreçte hastalardan ilaç tedavisi, diyet, egzersiz, stres yönetimi, sigara içimi ve günlük yaşam aktivitelerinde değişiklikler yapmaları da beklenebilmektedir. Hastaların genelde ilk 6 hafta içinde yaşadıkları bu fiziksel, psikolojik ve sosyal sorunlar yaşam kalitelerini de olumsuz etkilemektedir (Korkmaz vd., 2015; Lopez vd., 2007).

Açık kalp ameliyatı sonrası iyileşmeyi desteklemek için en sık kullanılan hemşirelik müdahalesi, risk azaltmaya ve ilaç, diyet ve aktivite rejimlerine uymaya odaklanan taburculuk eğitimleridir. Bununla birlikte, bu kapsamdaki eğitimler, hastanın erken evde iyileşme dönemindeki gerçek fiziksel ve psikososyal işlevi hakkında yeterli olmamaktadır. Bu nedenle bakımda hastaların iyileşme süreçlerini etkileyen faktörleri bilmek ve yaşam kalitelerini arttırıcı hemşirelik uygulamaları gerekmektedir (Lopez vd., 2007; Üstündağ ve Aslan 2011).

Açık kalp ameliyatları sonrasında hastaların iyileşme süreci ve yaşam kalitesine etkisini inceleyen çalışmalar kısıtlıdır (Aydın vd., 2002; Falcoz vd., 2003; Verwijmeren vd., 2018). Bu bağlamda açık kalp cerrahisi sonrasında hastaların yaşam kalitelerini değerlendiren bir ölçek Türkiye'de bulunmadığından, çalışma SIP 68 ölçeğinin ülkemize kazandırılması ve sonrasında hastaların açık kalp cerrahisi sonrası yaşam kalitelerini kapsayan fiziksel ve psikososyal iyileşme durumlarını değerlendirmek amacıyla yapıldı.

\section{Araştırma soruları}

- Hastalık Etki Profili 68, ülkemizdeki açık kalp ameliyatı uygulanan hastalarda kullanılabilecek geçerli bir araç mıdır?

- Hastalık Etki Profili 68, ülkemizdeki açık kalp ameliyatı uygulanan hastalarda kullanılabilecek güvenilir bir araç mıdır?

- Açık kalp ameliyatı geçiren hastaların fiziksel iyileşme durumları nasıldır?

- Açık kalp ameliyatı geçiren hastaların psikososyal iyileşme durumları nasıldır?

\section{YÖNTEM}

\section{Araştırma Modeli}

Bu araştırma, Hastalık Etki Profili-68 (SIP-68) Ölçeği'nin Türkçe'de geçerlik ve güvenirliğini incelemek ve açık kalp cerrahisi sonrası hastaların fiziksel ve psikososyal iyileşme durumlarının belirlenmesi amacıyla metodolojik ve tanımlayıcı-ilişki arayıcı olarak yapıldı.

\section{Örneklem/Çalışma grubu/Katılımcılar}

Araştırma bir kalp damar cerrahisi eğitim araştırma hastanesinde yürütüldü. Ölçek çalışması yapılırken, her bir ölçek maddesi için 5-10 kişi alınması önerildiğinden (Aksayan ve Gözüm 2002) bu araştırmada da her bir madde başına 10 kişi alınması planlandı. Araştırmanın evrenini Mart-Temmuz 2010 tarihleri arasında açık kalp ameliyatı olmak için başvuran hastalar oluşturdu. Araştırmanın örneklemini ise olasılıksız örneklem yöntemi ile seçilmiş araştırmaya katılmayı kabul eden 700 hasta oluşturdu. Ancak taburculuk sonrasında 9 hastanın araştırmaya katılmayı reddetmeleri nedeniyle, araştırma 691 kişi ile tamamlandı. Araştırmanın geçerlik güvenirlik çalışmasında ve hastaların iyileşme durumlarının tespit edilmesinde aynı hasta grubu kullanıldı. 


\section{Araştırmaya alınma kriterleri}

- Açık kalp ameliyatı geçirmiş olma,

- Taburculuk döneminde olma,

- Okur-yazar olma,

- İletişim güçlügü ve mental yetersizliği olmama,

- Araştırmaya gönüllü katılmadır.

\section{Veri Toplama Araçları ve Süreçleri}

Araştırma verileri, literatür (Sorensen ve Wang 2009; Pour ve Korkmaz 2010; Leegard vd., 2010; Korkmaz vd., 2015) doğrultusunda oluşturulan hasta tanıtım formu ve Hastalık Etki Profili 68 (deBruin ve ark 1994) ile Mart-Temmuz 2010 tarihleri arasinda topland.

Hasta Tanıtım Formu: Araştırmada hastaların sosyo-demografik özellikleri (cinsiyet, yaş, eğitim durumu, medeni durum, meslek, yaşadığ 1 yer, ekonomik durum) ile sağllk-hastalık durumuna ilişkin bilgilerinin (sigara/tütün kullanımı, spor yapma durumu, kronik hastalığın olup olmadığı, kullandığı ilaçlar, aile ve yakınları tarafından destek alınıp alınmadı $\breve{g} 1$ ) yer aldığ

Hastalık Etki Profili 68 (Sickness Impact Profile-SIP 68): Bu ölçek, kişinin günlük aktivitelerinin dışında yaptığı sağlıkla ilişkili davranışlarındaki değişimlerini ölçen, 136 maddeden oluşmaktadır. Her bir madde olası hastalık etkisini tanımlamaktadır. İlgili ölçeklerle kıyaslandığında Hastalık Etki Profili 68'in, çok uzun, zaman alıcı ve hastalar için yorucu olduğu ortaya çıkmaktadır. Bu nedenle Hastalık Etki Profili 68'in 68 maddelik kısa versiyonu deBruin ve ark (1994) tarafından geliştirilmiştir (deBruin ve ark 1994; Bergner ve ark. 1981).

Hastalık Etki Profili 68, tüm durumları/davranışları içeren 68 madde, 3 alt boyut, 6 alt gruptan oluşmaktadır.

- Fiziksel Altboyut; Beden Kısıtlılıkları ve Bağımsızlığı ile Hareket Kontrolü’nü,

- Psikolojik Altboyut; Fiziksel/Zihinsel Bağımsızlık ve İletişim ile Duygusal Denge’yi

- Sosyal AltBoyut; Sosyal Davranış ve Hareketlilik Sınırı'nı kapsamaktadır.

Hastalık Etki Profili 68'in maddeleri iki seçenekli bir cevaba uygundur [benim durumuma uygun (evet-evet 0 puan) ya da uygun değil (hayır-hayır 1 puan)]. Puanlama, 0 (en iyi sağlik) ile 68 (en kötü sağlık) arasında yer alır. Her alt gruptaki yüksek puan, sağlıkla ilişkili davranışlarda bir problem olduğunu gösterir. Ölçeğin iç tutarlılı̆̆ , toplam ölçek için .90 - .92 arasında; alt gruplar için .49 - .87 arasında değişmektedir. Test-retest güvenirliğinde, sınıflar arası korelasyon katsayısı toplam ölçek puanı için .97, alt boyutlarda ise .90 - .97 arasindadır (deBruin ve ark 1994).

Ölçeğin, dil çeviri süreci çalışmaları şu adımlardan oluşmuştu: 1-İngilizceden Türkçeye çeviri; 2-İkidilli (bilingual -Türkçe ve İngilizceyi iyi bilen) bir tercüman tarafından çevirinin, ölçeğin orijinal diline geri çevrilmesi; 3- Geri çevrilen ölçeğin İngilizce orijinali ile 5 çevirmen tarafından karşılaştırılması (bilingual Türkçe ve İngilizceyi iyi bilen); 4- Ölçek çevirisinin son hali ve özgün formu, hemşirelik alanında uzman öğretim üyesi 5 uzman tarafından değerlendirilmesi; 5- Uzmanların önerileri doğrultusunda ölçek son şeklinin verilmesi.

Kapsam geçerliği: Türkçe'ye çevrilen ölçek maddelerinin kapsam geçerliği için, 10 tane alanında uzman öğretim üyesinin görüşleri alındı. Kapsam geçerliğinin değerlendirilmesinde, Waltz ve Bausell (1981) tarafindan geliştirilen Kapsam Geçerlik İndeksi-KGİ (Content Validity Index-CVI) ve Kendall's W iyi uyuşum analizi kullanıldı ve uzmanlar arasında uyumun (Kendall's W: ,125 p: ,084) olduğu görüldü. 68 maddeden oluşan taslak ölçeğin pilot çalışması 10 hastada yapılarak, geçerlik güvenirlik çalışması için örneklem grubuna uygulandı.

Yap1 geçerliği: Çalışmada altboyutların/faktörlerin uyumunu doğrulamak amacıyla doğrulayıcı faktör analizi yapılmak istendiğinde veriler uygun bulunmamış ve model kurulamamıştır. 
Test-tekrar test güvenirliği: Çalışmada, ilk ve ikinci uygulamalar arasında 1 hafta süre bırakılarak örnekleme tekrar uyguland1.

\section{Araştırmanın Uygulanması}

Hastalık Etki Profili 68 Ölçeği’nin dil ve kapsam geçerliği çalışması 691 hasta ile tamamlandıktan sonra test-tekrar test uygulaması için 1 hafta sonra, 56 hasta ile yeniden görüşüldü. Yapılan güvenirlik analizleri sonrası, taburculuk döneminden 1 hafta sonra, polikliniğe kontrole gelen, araştırmayı kabul eden 56 hasta ile birebir görüşülerek, çalışmanın amacı açıklandıktan sonra hasta tanıtım formu ve Hastalık Etki Profili 68'in geçerli güvenilir bulunan maddeleri (11 madde) uygulandı. Formların doldurulması yaklaşık 15-20 dakika sürdü.

\section{Verilerin Analizi}

İstatistiksel analizler: Çalışma verileri Statistical Package for the Social Sciences (SPSS) 11.5 ile analiz edilmiştir. Güvenilirlik analizleri için Cronbach alfa güvenirlik kaysayısı, Pearson Korelasyon Analizi, Spearman Korelasyon analizi, bağımlı gruplarda t testi; geçerlik analizlerinde doğrulayıcı faktör analizi, Kendall's W iyi uyuşum analizi, kapsam geçerlik indeksi; tanımlayıcı ve karşılaştırmalı analizler ise yüzdelik dağılım, aritmetik ortalama, standart sapma, Pearson ki-kare, Fisher'in kesin ki-kare testi, Yates düzeltmeli ki-kare kullanıldı.

\section{Etik}

Hastalık Etki Profili 68 ölçeğinin Türkçe'ye çevrilmesi ve çoğaltılması için, ölçeği geliştiren kişilerden elektronik posta ile izin alınarak işbirliği sağlandı. Çalışmanın başlatılabilmesi için bir üniversitenin etik kurulundan (03/10/2008; 27567), çalışmanın ilgili hastanede yapılabilmesi için İl Sağlık Müdürlüğü etik kurulundan (02/06/2009; SG.B104İSM.4344743/1158) gerekli izinler alındı. Çalışma örneklemini oluşturan hastalardan da çalışmanın amacı sözel açılanarak onamları alındı. Çalışma açık kalp cerrahisi geçiren hastalar ve çalışmanın yapıldığı hastane ile sınırlandırılmıştır.

\section{BULGULAR}

Çalışmaya katılan hastalara ait bazı sosyodemografik özellikler ve hastalık/sağlık bilgisi Tablo 1'de gösterilmiştir.

Tablo 1. Hastalara Ait Bazı Sosyodemografik Özellikler ve Hastalık/Sağlık Bilgileri

\begin{tabular}{|c|c|c|c|c|c|}
\hline Özellikler & Sayı & $\%$ & Özellikler & Sayı & $\%$ \\
\hline Cinsiyet & \multicolumn{5}{|c|}{ Düzenli Spor Yapma Durumu } \\
\hline Kadın & 189 & 27.4 & Hayır & 626 & 90.6 \\
\hline Erkek & 502 & 72.6 & Evet & 65 & 9.4 \\
\hline Yaş & \multicolumn{5}{|c|}{ Sigara/ Tütün Kullanma Durumu } \\
\hline$<49$ & 152 & 22.0 & Hiç Kullanmadım & 303 & 43.8 \\
\hline $49-69$ & 387 & 56.0 & Evet & 143 & 20.7 \\
\hline 70 ve üstü & 152 & 22.0 & Biraktım & 245 & 35.5 \\
\hline Ĕgitim Durumu & \multicolumn{5}{|c|}{ Beden Kitle İndeksi } \\
\hline Okur-Yazar & 98 & 14.2 & Zayif & 2 & .3 \\
\hline İlkokul & 341 & 49.3 & Normal & 132 & 19.1 \\
\hline Ortaokul-Lise & 191 & 27.6 & Hafif şişman & 427 & 61.8 \\
\hline Üniversite ve Üzeri & 61 & 8.9 & $\begin{array}{l}\text { Obez } \\
\text { (1.derece şişman) }\end{array}$ & 130 & 18.8 \\
\hline Medeni Durum & \multicolumn{5}{|c|}{ Kronik Hastalık Varlığı } \\
\hline Evli & 686 & 99.3 & Hayır & 368 & 53,3 \\
\hline Bekâr & 5 & .7 & Evet & 323 & 46,7 \\
\hline Çalışma Durumu & \multicolumn{5}{|c|}{ Kronik Hastalık Sayısı } \\
\hline Evet & 497 & 71.9 & Yok & 368 & 53,3 \\
\hline Hayır & 194 & 28.1 & Tek Kronik Hastalık & 158 & 22,9 \\
\hline & & & İki-üç Kronik Hastalık & 165 & 23,8 \\
\hline
\end{tabular}




\begin{tabular}{|c|c|c|c|c|c|}
\hline \multicolumn{3}{|l|}{ Yaşadığı Yer } & \multirow{2}{*}{\multicolumn{3}{|c|}{$\begin{array}{l}\text { Hastalık Sırasında Aile ve Yakınlarından Destek Alma } \\
\text { Durumu }\end{array}$}} \\
\hline$\dot{\mathrm{I}}$ & 570 & 82.5 & & & \\
\hline $\begin{array}{l}\text { İlçe } \\
\text { Köy-Kasaba }\end{array}$ & $\begin{array}{l}67 \\
54\end{array}$ & $\begin{array}{l}9.7 \\
7.8\end{array}$ & $\begin{array}{l}\text { Hayır } \\
\text { Evet }\end{array}$ & $\begin{array}{l}4 \\
687\end{array}$ & $\begin{array}{l}, 6 \\
99,4\end{array}$ \\
\hline \multicolumn{3}{|l|}{ Ekonomik Durum } & \multicolumn{3}{|l|}{ Alınan Destek Türü } \\
\hline Gelir Giderden Az & 349 & 50.5 & Maddi ve Psikolojik & 174 & 25,2 \\
\hline \multirow[t]{3}{*}{ Gelir-Gider Dengeli } & 342 & 49.5 & Psikolojik/Sosyal & 517 & 74,8 \\
\hline & & & \multicolumn{3}{|c|}{ Aldığınız Destekten Ne Ölçüde Memnun Kaldınız? } \\
\hline & & & $\begin{array}{l}\text { Çok İyi } \\
\text { İyi }\end{array}$ & $\begin{array}{l}310 \\
381\end{array}$ & $\begin{array}{l}44,9 \\
55,1\end{array}$ \\
\hline
\end{tabular}

Tablo 2. Hastalı Etki Profili 68 ve Altboyutlarının Test-Tekrar Test Puan Ortalamalarının Karşılaştırılması ve Korelasyonlart (n: 56)

\begin{tabular}{|c|c|c|c|c|c|c|}
\hline ÖLÇEK VE ALT BOYUTLARI & $\begin{array}{l}\text { İLK } \\
\text { UYGULAMA } \\
\overline{\mathbf{x}}_{ \pm} \text {SS }\end{array}$ & $\begin{array}{l}\text { İKINCI } \\
\text { UYGULAMA } \\
\overline{\mathbf{x}}_{ \pm} \mathbf{S S}\end{array}$ & $\mathbf{T}^{* *}$ & $\mathbf{P}$ & $\mathbf{R}$ & $\mathbf{P}$ \\
\hline TOPLAM PUAN & $26.70 \pm 5.13$ & $27.11 \pm 4.98$ & 3.536 & .001 & .99 & .000 \\
\hline \multicolumn{7}{|l|}{ ANA BOYUTLAR } \\
\hline Fiziksel Boyut & $8.64 \pm .29$ & $9.00 \pm .95$ & 4.564 & .000 & .98 & .000 \\
\hline Psikolojik Boyut & $3.25 \pm .96$ & $3.30 \pm 1.32$ & .725 & .472 & .96 & .000 \\
\hline Sosyal Boyut* & $14.80 \pm 1.32$ & $14.80 \pm 3.22$ & $\mathbf{A Y} *$ & & $\mathbf{A Y} *$ & \\
\hline \multicolumn{7}{|l|}{ ALT BOYUTLAR } \\
\hline Beden Kısıtlılıkları Ve Bağımsızlığı & $4.39 \pm .98$ & $4.52 \pm .99$ & 2.803 & .007 & .94 & .000 \\
\hline Hareket Kontrolü & $4.25 \pm 2.35$ & $4.48 \pm 5.13$ & 4.078 & .000 & .98 & .000 \\
\hline Fiz./Zih.Bağimsizlik Ve İletişim & $1.13 \pm 4.98$ & $1.25 \pm .98$ & 2.803 & .007 & .98 & .000 \\
\hline Sosyal Davraniş** & $9.91 \pm .99$ & $9.91 \pm 2.35$ & $\mathbf{A Y} *$ & & $\mathbf{A Y} *$ & \\
\hline Duygusal Denge & $2.13 \pm 2.34$ & $2.05 \pm 1.61$ & 1.272 & .209 & .90 & .000 \\
\hline Hareketlilik Siniri* & $4.89 \pm 1.60$ & $4.89 \pm .29$ & $\mathrm{AY}^{*}$ & & $\mathbf{A Y} *$ & \\
\hline
\end{tabular}

*AY: Grupların ortalaması eşit olduğu için test yapılamadı. ** Bağımlı gruplarda t testi: serbestlik derecesi $=55$

Hastalık Etki Profili 68'in ve altboyutlarından, psikolojik altboyut ve duygusal denge alt grubunun 7 gün ara ile yapılan iki ölçümün puan ortalamaları arasında istatistiksel olarak anlamlı fark olmadığı (p>,05); sosyal altboyut ile altgruplardan sosyal davranış ve hareketlilik sınırının puanlarının eşit olduğu (farklı olmadığı); iki ölçümden elde edilen toplam ölçek, fiziksel altboyut ve altgruplardan beden kısıtlılıkları ve bağımsılılı̆ı, hareket kontrolü, fiziksel/zihinsel bağımsızlık ve iletişim puanlarının arasında ise anlamlı fark olduğu bulundu ( $\mathrm{p}<01$, Tablo 2). SIP 68'in güvenirlik analizi incelendiğinde; 7 gün ara ile yapılan ölçüm puanları arasında pozitif yönde, çok güçlü ve istatistiksel olarak çok anlamlı bir ilişki olduğu saptandı ( $p<.001$, Tablo 2). 
Tablo 3. SIP 68 ve Alt Boyutlarının Cronbach Alfa Güvenirlik Katsayıları (n=691)

\begin{tabular}{ll}
\hline ÖLÇEK VE ALT BOYUTLARI & $\boldsymbol{\mu}$ \\
\hline SIP 68 TOPLAM PUAN & $\mathbf{9 2}$ \\
\hline ANA BOYUTLAR & $\mathbf{. 9 2}$ \\
\hline Fiziksel Boyut & $\mathbf{. 7 0}$ \\
Psikolojik Boyut & $\mathbf{. 2 2}$ \\
Sosyal Boyut* & \\
\hline ALT BOYUTLAR & $\mathbf{. 6 9}$ \\
\hline Beden Kısıtlılıkları Ve Bağımsızlı̆̆ı & $\mathbf{9 2}$ \\
Hareket Kontrolü & $\mathbf{8 7}$ \\
Fiz./Zih.Bağimsizlik Ve İletişim & .12 \\
Sosyal Davraniş** & .03 \\
Duygusal Denge & $\mathbf{. 6 5}$ \\
\hline Hareketlilik Siniri* & \\
\hline
\end{tabular}

Hastalık Etki Profili 68'in ve ana ve altgruplarının cronbach alfa güvenirlik katsayısı tüm ölçek için $\propto=$ .92; sosyal davranış ve duygusal denge altgruplarında sırasıyla $\propto=.12$ ve .03 olarak çok düşük; diğer dört altgrup ve üç altboyutta $\propto=.65$ ile .92 arasında bulundu (Tablo 3).

Tablo 4. Hastalık Etki Profili-68'in Alt Boyutlarının Toplam Ölçekle Korelasyonları (n=691)

\begin{tabular}{|c|c|c|}
\hline \multirow[t]{2}{*}{ ALT BOYUT VE ALT GRUPLAR } & \multicolumn{2}{|c|}{$\begin{array}{l}\text { ALT BOYUT-TOPLAM ÖLÇEK KORELASYON } \\
\text { KATSAYISI }\end{array}$} \\
\hline & $\mathbf{r}$ & $\mathbf{p}$ \\
\hline \multicolumn{3}{|l|}{ ALT BOYUTLAR } \\
\hline Fiziksel Boyut & 0.97 & .000 \\
\hline Psikolojik Boyut & 0.92 & .000 \\
\hline Sosyal Boyut & 0.62 & .000 \\
\hline \multicolumn{3}{|l|}{ ALT BOYUTLAR } \\
\hline Beden Kısıtlılıkları ve Bağımsızlığı & 0.90 & .000 \\
\hline Hareket Kontrolü & 0.97 & .000 \\
\hline Fiziksel/Zihinsel Bağımsızlık ve İletişim & 0.96 & .000 \\
\hline Sosyal Davranı̧ & 0.51 & .000 \\
\hline Duygusal Denge & 0.16 & .000 \\
\hline Hareketlilik Sınırı & 0.53 & .000 \\
\hline
\end{tabular}

Hastalık Etki Profili 68'in altboyut ve altgruplarının toplam ölçekle ilişkisi pearson korelasyon analizi ile incelendiğinde, üç altboyutun güvenirlik katsayısının $\mathrm{r}=.62$ ile .97 arasında ve pozitif yönde olduğu ( $\mathrm{p}<.001$ ), altgruplardan duygusal dengenin güvenirlik katsayısının düşük olduğu $(r=.16)$, diğer beş altgrubun güvenirlik 
katsayılarının ise $r=.51$ ile .97 arasında, pozitif yönde ve istatistiksel olarak çok ileri düzeyde anlamlı olduğu saptand $1(\mathrm{p}<.001$, Tablo 4$)$.

Tablo 5. Hastalık Etki Profili-68 in Madde-Alt Boyut Puan ve Madde-Toplam Puan Korelasyonları ( $n=691$ )

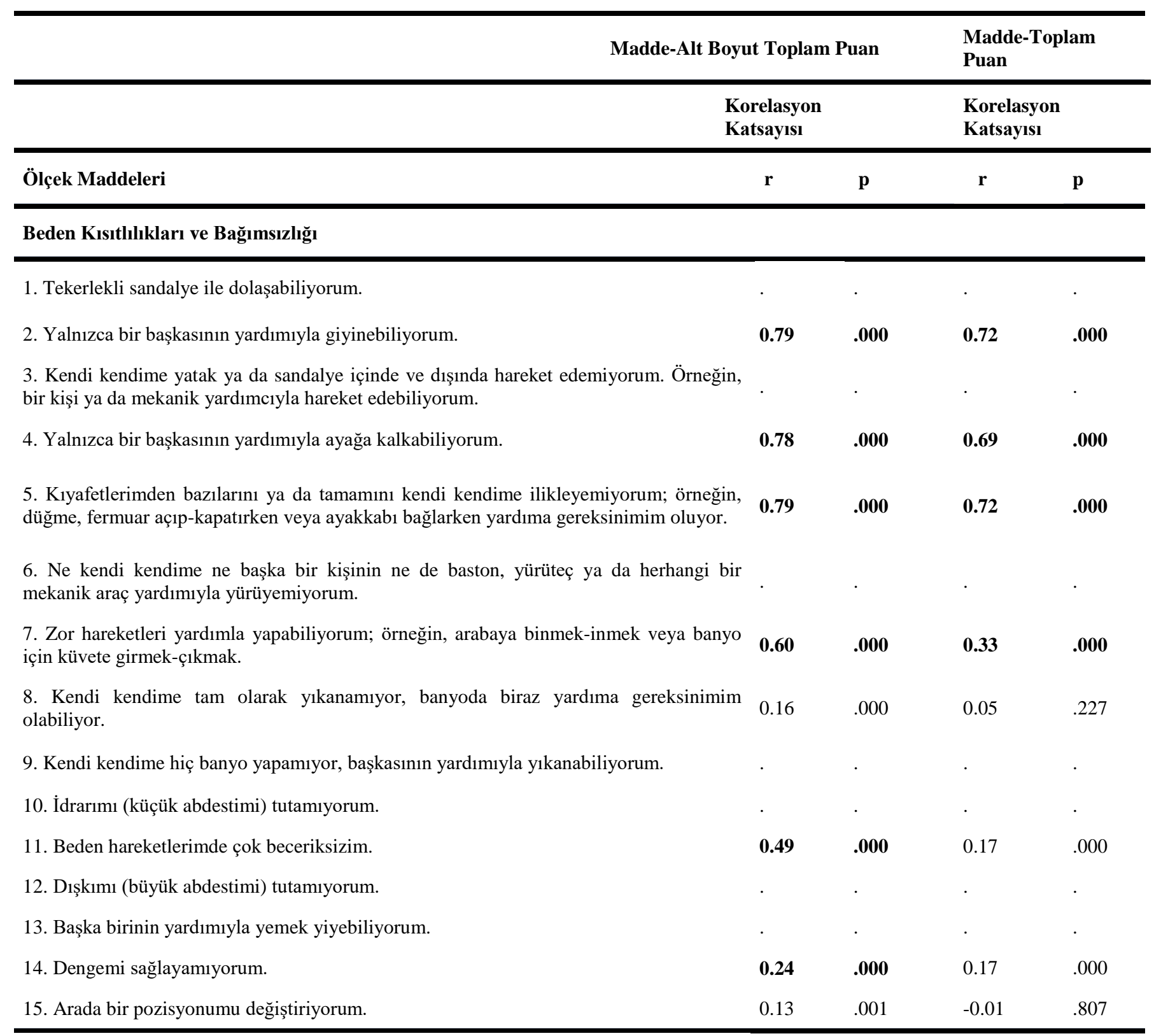

Fiziksel/Zihinsel Bağımsızlık ve İletişim

1. Ak1l yürütme ve sorun çözmede zorluk çekiyorum; örneğin, plan yapma, karar verme, yeni şeyler öğrenme.

2. Konsantrasyon gerektiren aktiviteleri yapmada zorluk çekiyorum.

3. Söylenen ya da yapılan şeylere yavaş tepki veriyorum.

4. Her zamankinden daha fazla hata yapıyorum.

5. Dikkatimi, uzun süre bir aktivite üzerinde tutamıyorum.

6. Yakın zamanda gerçekleşmiş birçok şeyi unutuyorum; örneğin, eşyaları koyduğum yer ya da randevular.

7. Kafam karışıyor ve bir defada birkaç işe başlıyorum.

8. Stres altındayken anlaşılır şekilde konuşamıyorum. 
9. Konuşurken zorluk çekiyorum; örneğin, takılıp kalmak, kekelemek, teklemek, kelimeleri gevelemek gibi.

10. Başladığım şeyleri bitiremiyorum.

0.76

11. Elle ya da daktilo ile yazmada zorlanıyorum.

\section{Sosyal Davranış}

1. Cinsel isteğim azaldı.

2. Arkadaşlarımla görüşmelerimin süresini azaltıyorum.

3. Daha az sivi alıyorum.

4. Toplumsal aktivitelere daha az katılıyorum.

5. Gruplarla yapılan sosyal aktivitelere daha az katılıyorum.

6. Eğlence için daha az sıklıkta dışarı çıkıyorum.

7. Evden yalnızca kısa süreliğine uzaklaşıyorum.

8. Yemekli toplantılara daha az katılıyorum.

9. Evde ağır işleri yapmıyorum.

10. Hobilerimi yapmak ve dinlenmek için daha az zaman ayırıyorum.

11. Evde her zaman yaptığımdan daha az günlük iş yapıyorum.

12. Boş zamanlarımda vaktimi değerlendirdiğim meşgalelerimi azalttım.
0.92

.000

$\mathbf{0 . 5 0}$

.000

0.52

000

0.32

.000

$0.06 \quad .108$

0.05

.184

\section{Duygusal Denge}

1. Etrafımdakilere karşı, sinirli davranışlarda bulunuyorum; örneğin, insanları tersleme, sert cevaplar verme ve kolayca eleştirme.

2. Aile üyelerine karşı uyumsuz davranıyorum; örneğin, onları kırıyorum ve inatçıyım.

3. Aile üyelerine karşı sık sık öfke patlamaları yaşıyorum; örneğin, onlara vurma, bağırma, bir şeyler firlatma gibi.

4. Kendime karşı sinirli ve sabırsızım; örneğin, kendim hakkında kötü konuşma, kendime küfretme, meydana gelen olaylar yüzünden kendimi suçlama.

5. Aile üyeleriyle genellikle yaptığım gibi şakalaşmıyorum.

0.37

.000

\section{Hareketlilik Sınırı}

1. Her zaman yaptığım alışverişlerin hiçbirini yapamıyorum.

2. Çarşıya gidemiyorum.

3. Her zaman yaptığım ev temizliğini hiç yapmıyorum.

4. Evde her zaman yaptığım düzenli günlük işlerin hiçbirini yapamıyorum.

5. Zamanımın çoğunu evde geçiriyorum.

6. Her zaman yaptığım çamaşır yıkama işini hiç yapmıyorum.

7. İnsanları ziyaret etmek için hiç dışarı çıkmıyorum.

8. Kişisel veya evle ilgili mali işlerle ilgilenmeyi bıraktım; örneğin, fatura ödeme, banka işlemleri ya da bütçe çalışması. 
Hastalık Etki Profili-68'in alt boyutlarının güvenirlik çalışması için alt boyut maddelerinin alt boyut toplam puanları ile korelasyonlarına bakıldığında, korelasyon güvenirlik katsayılarının (Spearman Korelasyon Analizi);

Beden kısıtllılıları ve bağımsızlığı boyutunda 7 maddenin (1, 3, 6, 9, 10, 12 ve 13. maddeler), Hareket kontrolü boyutunda; 2 maddenin (3 ve 12. maddeler), Fiziksel/zihinsel bağımsızlık ve iletişsim boyutunda; 5 maddenin (4, 7, 8, 9 ve 11. maddeler), Sosyal davranış boyutunda; 9 maddenin (2, 5, 6, 7, 8, 9, 10, 11 ve 12. maddeler), Duygusal denge boyutunda; 1 maddenin (3. madde), Hareketlilik sinirl boyutunda; 2 maddenin (1 ve 9. maddeler) olmak üzere toplam 26 maddenin madde-grup toplam puan güvenirlik katsayısının hesaplanamadığ saptand1.

Ölçeğin 12 maddesinin (Beden kısıtll1ıkları ve bağımsızlığı boyutunda 8, 11, 14, 15., Hareket kontrolü boyutunda 7. madde, Sosyal davranış boyutunda 4. madde, Duygusal denge boyutunda 1 ve 4 . maddeler, Hareketlilik sınırı boyutunda 2, 5 ve 7. maddeler) madde-toplam puan güvenirlik katsayıs1 $\mathrm{r}=.20$ 'nin altında olarak düşük bulundu.

Ölçeğin 27 maddesinin (Beden kısıtlılıkları ve bağımsızlı̆̆ı boyutunda 2, 4, 5 ve 7. maddeler, Hareket kontrolü boyutunda 1, 2, 4, 5, 6, 8, 9, 10 ve 11. maddeler, Fiziksel/zihinsel bağımsızlık ve iletişim boyutunda 1, 2, 3, 5, 6 ve 10. maddeler, Sosyal davranış boyutunda 1 ve 3. maddeler, Duygusal denge boyutunda 5 ve 6. maddeler , Hareketlilik sınırı boyutunda 3, 4, 6 ve 8. maddeler) güvenirlik katsayıları r= .32 ile .72 arasında, pozitif yönde ve istatistiksel olarak çok anlamlı düzeyde olduğu saptandı ( $\mathrm{p}<.001$, Tablo 5).

Araştırmada kullanılan SIP 68'in, yapılan istatistikler sonucunda bazı maddelerinin geçerlik güvenirliğinin yeterli olmadığı görüldü ve bu maddeler çıkarıldı. Kalan maddeler arasında benzer anlamı taşıyan ifadeler birleştirildi. Bunlar;

-Beden kısıtılılıkları ve bağımsızlı̆̆ı boyutunun 2 ve 5 . maddeleri ile hareket kontrolü boyutunun 11 . maddeler birleştirildi ve "bir başkasının yardımıyla giyinebilme, el işlerini yapmakta zorluk çekme", Hareket kontrolü boyutunun 1, 2 ve 8. maddeleri birleştirilerek "yavaş yürüme, sık dinlenme, oturup kalkarken destek alma",Fiziksel/zihinsel bağımsızlık ve iletişim boyutunun 1 ve 6 . maddeleri birleştirilerek "akıl yürütme/sorun çözmede zorluk çekme, yakın zamanda gerçekleşmiş birçok şeyi unutma" şeklinde kullanıldı ve bu maddeler ile hastaların tanıtıcı özellikleri arasında karşılaştırmalar yapıldı.

Hastaların bazı sosyodemografik ve hastalık/sağlık özelliklerine (yaş, cinsiyet, eğitim durumu, sigara kullanma, spor yapma, beden kitle indeksi ve aileden alınan destek) ilişkin veriler ile ölçeğin alt boyutlarından (fiziksel davranış, sosyal/psikolojik davranış, bilişsel/cinsel davranış) aldıkları puan ortalamaları dağılımı incelenmiş ve gruplar arasında istatistik olarak anlamlı fark olduğu saptanmıştır ( $\mathrm{p}<.01)$.

\section{TARTISMA}

Bu çalışmada, Hastalık Etki Profili 68 ölçeğinin Türkçe'de geçerlik güvenirlik incelemesi ve açık kalp cerrahisi sonrası hastaların fiziksel ve psikososyal iyileşme durumlarının belirlenmesi ve ölçek puanlarının hastaların bazı özellikleri ile karşılaştırılması amacıyla yapıldı. Hastalık Etki Profili 68 Ölçeği’nin Türkiye için uygun bir ölçek olmadığı, hastaların fiziksel, psikososyal iyileşme durumlarının taburculuk sonrası ilk dönemlerde yeterli olmadığ

Ölçeğin farklı hastalıklar üzerinde yapılan çalışmalarında Cronbach Alpha katsayıları da farklı bulunmuştur. Post ve diğerlerinin (1996) spinal kord yaralanması olan hastalar üzerinde yaptıkları çalışmada, Cronbach Alpha katsayısı, toplam ölçek için .90; alt boyutlar için .50-.90 arasında; test-retest güvenirliğinde, korelasyon katsayısı, toplam ölçek puanı için .98 , alt boyutlarda ise $.90-.96$ arasında değiştiği saptanmıştır. Bedensel sinırlılığı olan hasta grubunda SIP-68'in SIP ile karşılaştırıldığı bir çalışmada, Cronbach Alpha katsayısı, toplam ölçek için .94; alt boyutlar için .50-.90 arasında; test-retest güvenirliğinde, korelasyon katsayıs1 toplam ölçek puanında .88, alt boyutlarda ise .79 -.93 arasında bulunmuştur (Nanda vd., 2003). Yoğun bakım ünitesinde uzun süreli kalan hastaların değerlendirilmesinde SIP ve Modified Short Form (MSF)'un karşılaştırıldığı çalışmada, SIP'in Cronbach Alpha katsayısı .95 olarak diğer ölçekten daha yüksek bulunmuştur 
(Lipsett vd., 2000). Yine SIP-68'in farklı hastalıklar ve farklı yaşam kaliteleri ölçekleri arasında karşılaştırmaların yapıldığı çalışmalarda da benzer sonuçlar elde edilmiştir (Kenna vd., 2005; Nanda vd., 2003; Pollard ve Johnston 2001). Ancak Jansen ve diğerlerinin (2010) çalışmasında, 7 alt boyutun Cronbach Alpha katsayısı .70'in üzerinde, 5 alt boyutun ise çok düşük olduğu ve çalışma hipotezlerine uyum sağlamadığı saptanmıştır. Ölçeğin farklı ülkelerde yapılan geçerlik güvenirlik çalışmalarında da literatürde farklılık gözlenmektedir. Benaim ve diğerlerinin (2003), SIP'in Fransa dili için afazik hastalarda geçerlik güvenirliğini yaptıkları çalışmalarında, ölçeğin 65 soru içeren 8 alt boyutunu kullanmışlar ve Cronbach Alpha katsayısını .97 olarak saptamışlardır. SIP'in Alman dilinde kas iskelet hastalıkları üzerinde geçerlik güvenirliğini belirlemek üzere yapılan bir çalışmada ise toplam ölçek için Cronbach Alpha katsayıs1 .83, test-retest güvenirliği ,81 olarak bulunmuştur (Kessler vd., 1997). Hütter ve Würtemberger (1997) tarafından SIP'in Alman dilinde geçerlik güvenirliğini belirlemek üzere kronik obstrüktif akciğer hastalarında yapılan çalışmada toplam ölçek için Cronbach Alpha katsayıs1 .93 iken alt boyut için .55-.86 arasında bulunmuştur. Beslenme alt grubunda Cronbach Alpha katsayısı .40; fiziksel ve psikososyal alt boyutlarda ise .19-.48 arasında oldukça düşük bulunduğundan bazı alt boyutların yeniden düzenlenerek ya da çalışmadan çıkarılmasıyla ölçeğin kullanılabileceği belirtilmiştir. İtalya'da SIP'in geçerlik güvenirliğinin farklı hastalar üzerinde yapıldığı çalışmalarda, Cronbach Alpha katsayısı .86 ve .98 olarak tespit edilmiştir (Badia ve Alonso 1999; Monticone vd., 2010).

Bu çalışmada, Cronbach Alpha katsayısı toplam ölçek için .92; ölçeğin sosyal davranış ve duygusal denge alt gruplarında .12 ve .03 olarak çok düşük; diğer dört alt grup ve üç boyutta $.65-.92$ arasında bulunmuştur. Testretest güvenirliğinde ise, sınıflar arası korelasyon katsayısı toplam ölçek puanı için .99, alt boyutlarda ise $.90-.98$ arasında saptanmıştır. Bu sonuca bağlı olarak çalışmada beden kısıtlıkları ve bağımsızlık boyutunda 11 madde, hareket kontrolü boyutunda 3 madde, fiziksel/zihinsel bağımsızlık ve iletişim boyutunda 5 madde, sosyal davranış boyutunda 10 madde, duygusal denge boyutunda 3 madde, hareketlilik sınırı boyutunda 5 madde ölçekten çıkarılmıştır. Literatür ile karşılaştırıldığında bu çalışma bulgusu, Hütter ve Würtemberger (1997) ile Jansen ve diğerlerinin (2010) çalışma sonuçlarındaki cronbach alfa katsayısını desteklemekle birlikte, altboyutlara ilişkin güvenirlik katsayılarının farklı olarak bu çalışmada oldukça düşük olduğu; diğer çalışma bulgularıyla parallelik göstermediği gözlendi. Çıkarılan maddelerin, ülkemizin diğer ülkelere göre sosyo-kültürel yapısının farklı olduğunu, hastaların ülkelere göre bireysel özelliklerinin çalıșma bulguları üzerinde etkili olduğunu göstermekte ve ölçeğin tüm maddelerinin kullanımı yerine hastaların sınırlılıkları dikkate alınarak, uygun alt boyutların kullanılmasının daha iyi sonuçlar vereceğini düşündürmektedir.

Açık kalp cerrahisinin olumlu etkilerinin ve tedavi ediciliğinin yanısıra ameliyat sonrası dönemde fiziksel ve psikososyal sorunlara neden olabilmektedir. Bu durum hastaların yaşam kalitelerini etkilemektedir. Yaşam kalitesinde fiziksel iyilik hali, fiziksel hareketleri yapmada güçlük, fonsiyonel yetersizlik, çalışma durumu, hastalık semptomları ve sağlık durumu ile ilgili konular objektif göstergeleri; psikolojik/duygusal iyilik hali ve yaşam doyumu ile ilgili konular subjektif göstergeleri kapsamaktadır (Dirimeşe, Korkmaz, Alcan 2016). Fiziksel iyilik halinde cinsiyet (Gjeilo vd., 2008; Leegard vd., 2010; Spiroski vd., 2017), yaş (Kattainen vd., 2006; Simko ve McGinnis 2005), sigara/tütün kullanımı (Halpin vd 2008; Sadeghi vd., 2017), beden kitle indeksi (Barnett vd., 2010; Martin vd., 2008), gibi faktörler etkilidir. Literatürle uyumlu çalışma bulguları, hemşirelik bakımında bu parametrelerin bütüncül bakımı sağlamada önemli olduğunu da göstermektedir. Hemşirelik bakımında bütüncü yaklaşımda birey/hasta fizyolojik-psikolojik-sosyal boyutlarıyla ele alınmalı ve bireyselleştirilmiş bakım ön plana çıkmalıdır. Bu amaçla verilen bakımda da yaş, cinsiyet, beden kitle indeksi, alışkanlıklar gibi faktörlerin ele alınması önem kazanmaktadır.

Açık kalp cerrahisi hastalarda günlük aktivitelerin kısıtlanması, gelecekte hastalığın ilerleyeceği kaygısı oluşturduğu için hasta yakınlarının psikolojik ve sosyal destekleri çok önemlidir. Yapılan farklı iki çalışmada aile desteği alan KABG hastalarının, fiziksel, sosyal ve psikolojik davranışlardaki iyileşmelerinin aile desteği almayan gruba oranla çok daha yüksek; yaşlı bireylerde bu desteğinin olumlu etkisinin daha fazla olduğu bulunmuştur (Lenz ve Perkins 2000; Sadeghi vd., 2017; Sorensen ve Wang 2009). Çalışmada literatür bilgileriyle uyumlu olarak hastaların \%99.4'ünün hastalıkları sırasında aile yakınlarından destek aldığı; bu alınan desteğin \%74.8'inin psikolojik/sosyal boyutta olduğu bulundu. Literatürle uyumlu bu sonuç, hasta bakımında aile desteğinin önemli 
olduğunu, hemşirelik bakım planı oluştururken hasta ailesi ve yakınlarının da bakıma dahil edilmesi gerektiğini desteklemektedir.

\section{SONUÇ VE ÖNERILER}

Bu bağlamda Hastalık Etki Profili 68 Ölçeği'nin Türkiye'de, başka bir hasta grubuna uygulanarak geçerlik güvenirlik çalışmasının yeniden yapılması, aynı hasta grubunda daha farklı zaman aralıklarıyla uygulanarak geçerlik güvenirliğinin tekrar edilmesi, ameliyat sonrası hastaların fiziksel, sosyal/psikolojik ve bilişsel/cinsel davranışlardaki iyileşme süreleri ilk 6 aydan sonra daha iyi olduğu düşünülerek, yapılacak çalışmaların uzun süreleri kapsayacak şekilde planlanması ve hemşirelerin bütüncül bakımı sağlamada hastaların fiziksel iyilik halleri kadar psikososyal iyilik hallerini de geliştirerek yaşam kalitelerinde yükselme sağlayacak bakım planları oluşturmalı önerilmektedir.

Finansal destek: Herhangi bir finansal destek alınmamıştır.

Çıkar çatışması: Çalışmada çıkar çatışması yoktur.

\section{Yazarlık Katkıları:}

Tasarım/Design: S.K., N.K.; Veri toplama veya Veri Girişi Yapma/Data Collection or Processing: S.K.;

Analiz ve Yorum/Analysis or Interpretation: S.K.; Literatür Tarama/Literature Search: S.K.; Yazma/Writing: S.K., N.K.

\section{KAYNAKLAR}

Aksayan, S., \& Gözüm, S. (2002). Kültürlerarası Ölçek Uyarlaması İçin Rehber I: Ölçek Uyarlama Aşamaları ve Dil Uyarlaması. HEMAR-G Hemşirelik Araştırma Dergisi, 4(1):9-14.

Aydın, S., Yavuz, T., Düver, H., \& Kutsal, A. (2002) .65 yaş üstü hastalarda koroner bypass operasyonlarının yaşam kaliteleri üzerine erken dönem etkisinin SF-36 testi ile tespiti. Geriatri, 5 (2), 64-67.

Barnett, S.D., Martin, L.M. \& Halphin, L.S. (2010). Impact of body mass index on clinical outcome and health-related quality of life following open heart surgery. J Nurs Care Qual., 25(1), 65-72.

Bergner, M., Robbit, R.A., Carter, W.B. \& Gilson, B.S. (1981). The sickness impact profile: development and final revision of a health status measure. Medical Care, 19(8), 787-805.

De Bruin, A.F., Buys, M., De Witte, .LP., \& Diederiks, J.P. (1994). The sickness impact profile: SIP68, a short generic version. First evaluation of the reliability and reproducibility. J Clin Epidemiol., 47(8), 863-71.

Dirimeşe, E., Korkmaz, F.D., \& Alcan, A.O. (2016). Koroner arter by-pass greft cerrahisi öncesi hastaların yaşam kalitesi ve sağlıklı yaşam biçimi davranışlarının incelenmesi. Balikesir Saglik Bil Derg., 5(2), 56-61.

Doğu, Ö., Güngörsün, H.Ç., \& Erkorkmaz, Ü. (2015) Koroner by-pass ameliyatı olan hastalarda yaşam kalitesinin incelenmesi. J Hum Rhythm, 1(3), 155-161.

Falcoz, P.E., Chocron, S., Stoica, L., Kaili, D., Puyraveau, M., \& Mercier, M. (2003) Open heart surgery: one-year selfassessment of quality of life and functional outcome. Ann Thorac Surg., 76,1598-604.

Gjeilo, K.H., Wahba, A., Klepstad, P., Lydersen, S., \& Stenseth, R. (2008). The role of sex in health-related quality of life after cardiac surgery: a prospective study. Eur J Cardiovasc Prev Rehabi., 15, 448-52.

Halpin, L.S., Banett, S.D., Martin, L.S., Hunt, S.L., Henry, L. Ad, N. (2008). Survival and quality of life following elective open-heart surgery. J Nurs Care Qual., 23(4), 369-74.

Kattainen, E., Merilainen, P., \& Sintonen, H. (2006). Sense of coherence and health-releated quality of life among patients undergoing coronary artery bypass grafting or angioplasty. European Journal of Cardiovascular Nursing, 5, 21-30.

Korkmaz, F.D., Alcan, A.O., Aslan, F.E., \& Çakmakçı, H. (2015) Koroner arter baypas greft ameliyatı sonrası yaşam kalitesinin değerlendirilmesi. Turk Gogus Kalp Dama., 23(2), 285-294.

Leegard, M., Rustoen, T., \& Fagermoen, M.S. (2010). Interference of postoperative pain on women's daily life after early discharge from cardiac surgery. Pain Management Nursing, 11(2), 99-107.

Lenz, E.R. \& Perkis, S. (2000). Coronary artery bypass graft surgery patients and their family member caregivers: Outcomes of a family-focused staged psychoeducational intervention. Applied Nursing Research, 13(3), 142-50.

Lopez, V., Ying, C.S., Poon, C.Y., \& Wai, Y. (2007) .Physical, psychological and social recovery patterns after coronary artery bypass graft surgery: A prospective repeated measures questionnaire survey. International Journal of Nursing Studies, 44, 1304-1315.

Martin, C.G., Sandra, L. \& Turkelson, S.L. (2008). Nursing care of the patient undergoing coronary artery bypass grafting. 
Journal of Cardiovascular Nursing, 21(2), 109-17.

Onat, A., Can, G. (2017). Erişkinlerimizde kalp hastalıkları prevalansı, yeni koroner olaylar ve kalpten ölüm sıklığı. In: A. Onat (Ed), Tıp dünyasının kronik hastalıklara yaklaşımına öncülük (20-29).

Pour, H.A., Korkmaz, F.D. (2010) Açık kalp cerrahisi sonrası hemşirelik bakımı. Ege Üniversitesi Hemirelik Yüksek Okulu Dergisi, 26 (1), 77-86.

Republic of Turkey Ministry of Health (2015). Prevention and control program of cardiovascular diseases in Turkey 20152020. Retrieved from https://www.tkd.org.tr/TKDData/Uploads/files/Turkiye-kalp-ve- damar-hastaliklari-onleme-vekontrol-programi.pdf. 22.09.2020

Sadeghi, M., Hashemi, M., Sararoudi, R.B., Merasi, M.R., Molaeinezhad, M., \& Shamsolketabi, H. (2017). Demographic and psychological predictors of recovery from coronary artery bypass graft. Journal of Education and Health Promotion, $6,1-13$.

Simko, L.C. \& McGinnis, K.A. (2005). What is the perceived quality of life of adults with congenital heart disease and does it differ by anomaly?. Journal of Cardiovascular Nursing, 20(3); 206-14.

Sorensen, E.A. \& Wang, F. (2009). Social support, depression, functional status and gender differences in older adults undergoing first-time coronary artery bypass graft surgery. Heart \& Lung, 38, 306-17.

Spiroski, D., Andjic, M., Stojanovic, O.I., Lazovic, M., Dikic, A.D., Ostojic, M., Beleslin, B., Kostic, S., Zdravkovic, M., \& Lovic, D. (2017). Very short/short-term benefit of inpatient/outpatient cardiac rehabilitation programs after coronary artery bypass grafting surgery. Clinical Cardiology, 40, 281-286.

Şencan, H. Sosyal ve Davranışsal Ölçümlerde Güvenirlik ve Geçerlilik, Seçkin Yayıncılık Sanayi ve Ticaret A.Ş. 2005 Ankara.

Tung, H.H., Wei, J. \& Chang, C.Y. (2007). Gender differences in quality of life for post coronary artery bypass grafting patients in Taiwan. J. Nursing Research., 15(4), 275-83.

Üstündağ, H., \& Aslan, F.A. (2011). Koroner arter by-pass greft cerrahisi uygulanan hastanın bakımı ve konforu. Yoğun Bakım Hemşireliği Dergisi, 15(1), 22-28.

Verwijmeren, L., Noordzij P.G., Daeter E.J., Zaane B., Peelen L.M. \& Dongen E.P.A. (2018) Preoperative determinants of quality of life a year after coronary artery bypass grafting: a historical cohort study. Journal of Cardiothoracic Surgery, 13 (18), 2-8.

World Health Organization (WHO) (2017). Cardiovascular diseases (CVDs). Retrieved from http://www.who.int/mediacentre/factsheets/ fs317/en/ 22.09.2020. 


\section{EXTENDED ABSTRACT}

Introduction: Open heart surgery is an effective method for increasing patients 'quality and length of life and preventing potential complications of the disease. After the surgery patients may face a number of complications such as deterioration in cardiac, respiratory, gastrointestinal, fluid volume and neurological functions, as well as pain, renal insufficiency and electrolyte imbalance. Due to the vital importance of heart and intense fear of death, patients and their family will perceive the heart surgery as a great crisis and undergo emotional and psychological changes. The most commonly used nursing intervention to support recovery after open heart surgery is discharge training that focuses on risk reduction and adherence to medication, diet, and activity regimens. However, training in this scope is not sufficient about the actual physical and psychosocial function of the patient during the early home recovery period. For this reason, it is necessary to know the factors that affect the healing processes of patients in care and nursing practices that increase their quality of life.

This study was conducted as a methodological, descriptive and relation-seeking study to examine the Turkish validity and reliability of the Sickness Impact Profile-SIP 68 Scale and to determine the physical and psychosocial recovery of patients after the open heart surgery.

Research questions;

-Is Disease Impact Profile 68 a valid tool that can be used in patients undergoing open heart surgery in our country?

-Disease Impact Profile 68, is a reliable tool that can be used in patients undergoing open heart surgery in our country?

-What are the physical recovery conditions of patients who have undergone open heart surgery?

-How are the psychosocial recovery status of patients who have undergone open heart surgery?

Materials and Methods: In this study the sample was selected using the simple random sampling method. The sample comprised 700 patients who were nearly ten times greater than the item number of the scale, which was examined in terms of validity and reliability in the study and has a total of 68 items. However, as nine patients refused to take part in the study after the discharge, the study was completed with 691 people.

The data in the study were collected using the patient introduction form and SIP 68 Scale. In the validity study for the scale; language, content and construct validity were demonstrated. In the reliability study; the internal consistency was determined calculating the Cronbach's alpha coefficient and using item analyses and semi-test reliability methods. The Principal Component Analysis and Varimax rotation method were used in examining the exploratory factor analysis and factor structure for the construct concept validity. The patient introduction form comprises 21 questions about patients ' socio-demographic characteristics (gender, age, educational background, marital status, occupation, surrounding area, economic condition, presence of health insurance) and health-disease-related data (smoking/using tobacco, using alcohol, doing exercise, hospital experience, presence of chronic illness, medications taken, time of complaints about the disease, presence of complications, receiving support from family and relatives).

Findings: The Cronbach's alpha reliability coefficient for the total SIP 68 was $\propto=.92$. The reliability coefficient for the three lower dimensions ranged from $\mathrm{r}=.62$ to .97 in a positive direction $(\mathrm{p}<.001)$. Among the subgroups, emotional balance had a lower reliability coefficient $(\mathrm{r}=.16)$. The reliability coefficient for the other five subgroups ranged from $\mathrm{r}=.51$ to .97 and was statistically significant way in a positive direction. Age, gender, smoking, body mass index, doing exercise and receiving support from family and relatives, which are among demographic characteristics, affected the patients physical, social/psychological and cognitive/sexual behaviors. The second stage compared the patients 'gender, age, smoking, body mass index, doing exercise and receiving support from family with the items of the SIP 68 which were found to be valid and reliable. Of the patients, $72.6 \%$ were male, $56 \%$ were between the ages of $49-69,99.3 \%$ were married, $43.8 \%$ did not smoke/use tobacco, $98 \%$ did not use alcohol, $90.6 \%$ did not do exercise regularly, $61.8 \%$ were slightly fat compared to their body mass index and $99.4 \%$ received support from their family and relatives during disease. This support was mainly (74.8\%) psychological/social.

Discussion: There are validity and reliability studies for the SIP 68 Scale conducted in different countries. The Cronbach's alpha coefficient was found to be .86 in the study conducted by Monticone et al. in Italy (2010); .97 in the study conducted by Benaim et al. in France (2003); .83 in a study conducted in Germany (Kessler et al., 1997). This study determined the Cronbach Alpha coefficient for the total scale to be .92 . Additionally in contradistinction to other studies, the study found the reliability coefficients in the lower dimensions of the scale to be very low.

Conclusion and Recommendation: The SIP 68 Scale which is aimed to be brought in Turkey after demonstrating the validity and reliability analyses, is clearly not an appropriate scale for Turkey. The patients' physical and psychosocial recovery was not adequate during the early times of the discharge. In this context it is recommended that the SIP 68 Scale be applied to another patient group in Turkey to redemonstrate its validity and reliability; the scale be applied in the same patient group in different times to repeat its validity and reliability; further studies be planned in the long-term considering that the time of postoperative recovery in patients 'physical, social/psychological and cognitive/sexual behaviors is better after the sixth month. 